\title{
Beta spectrometry for environmental radioactivity measurements
}

\author{
A. Courti, P. Bouisset and P. Chevallier ${ }^{1}$ \\ Laboratoire de Mesure de la Radioactivité de l'Environnement (LMRE), IPSN, \\ bâtiment 501, Bois des Rames, 91400 Orsay cedex, France \\ ${ }^{1}$ Laboratoire pour l'Utilisation du Rayonnement Électromagnétique (LURE), \\ bâtiment 209D, Université Paris-Sud, 91405 Orsay cedex, France
}

\begin{abstract}
Various anthropogenic sources contribute to the inventory of long lived beta emitters in the environment $\left({ }^{40} \mathrm{~K},{ }^{210} \mathrm{~Pb},{ }^{60} \mathrm{Co},{ }^{137} \mathrm{Cs},{ }^{90} \mathrm{Sr},{ }^{90} \mathrm{Y}\right)$. Studies have been carried out to obtain the ${ }^{90} \mathrm{Sr}$ distribution in environment in order to estimate its impact in terms of radiation exposure to humans.

It is routinely measured it by proportional counter after radiochemistry. An incomplete radiochemical separation leads to a deposit submitted to count polluted by natural beta emitters. In order to guarantee results, ${ }^{90} \mathrm{Y}$ daughter of ${ }^{90} \mathrm{Sr}$, is systematically extracted from the final radiochemical fraction and counted. The ${ }^{90} \mathrm{Y}$ decreasing $\left(T_{1 / 2}=2.67\right.$ days) is checked by 2 hours successive counts during 64 hours. The delay between the end of radiochemistry and the counting is 15 days imposed for the radioactive equilibrium between ${ }^{90} \mathrm{Sr}$ and ${ }^{90} \mathrm{Y}$ to be reached. The duration from the beginning of the radiochemistry to the result of the measurement is of the order of five weeks.

In order to diminish this procedure, and in order to detect several radionuclides simultaneously, we study the possibility of a beta spectrometer based on two PIPS (Planar Passivated Implanted Silicon () Canberra) solid detectors. Because of their different $\beta_{\max }$ energies and to their spectral features (continuum shape, conversion electrons), we have shown that the main radionuclides like ${ }^{137} \mathrm{Cs}$ and ${ }^{90} \mathrm{Sr}$ can be discriminated. The identification is independent of the source geometry. However, the quantification requires a well defined and reproducible geometry, for which a shorter radiochemical procedure is being studied. Real sample results will be presented.
\end{abstract}

\section{INTRODUCTION}

Various anthropogenic source contribute to the inventory of long lived $\beta$-emitters in the environment. A beta emitter like strontium- 90 constitutes a long-term biological hazard as it accumulates in bone tissues and has a long physical and biological half-lives ( 28.6 and 49.3 years, respectively).

Other beta emitters like chlorine-36 can be of interest for environmental or human exposure [1]. Activity determination of pure beta emitters were usually made with a time consuming radiochemistry analysis. In post-accidental situation, a gross beta counting must be performed followed by other determination to identify radionuclides (artificial and natural).

Never developed, a beta spectrometry technique must give more accurate information for environmental studies as for post-accidental expertise. We propose this spectrometry approach using common PIPS detectors, generally used for alpha measurement, and with an analysis based on reference spectra. Direct measurements and shortened radiochemistry preparations were tested. Results shows the capability of the spectrometry for the beta emitters case. 


\section{PRINCIPLE}

\subsection{Alpha and Gamma Spectrometry}

Alpha and gamma spectrometries are well-known techniques for nuclide quantification. Detection of suth emitters is made easier by a discrete energy rays emission spectrum [2-4]. For example, Figure 1 represents a ${ }^{137} \mathrm{Cs}$ and ${ }^{214} \mathrm{Bi}$ gamma spectrum and Figure 2 represents a Pu alpha spectrum. If the detector resolution is sufficient, peaks can be easily resolved, otherwise peak deconvolution can be applied to determine contribution of each emitter component.

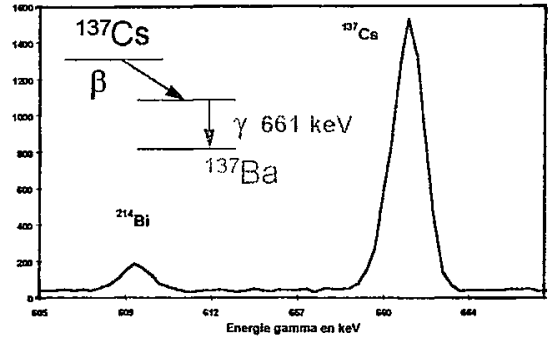

Figure 1: GeHp gamma spectrum

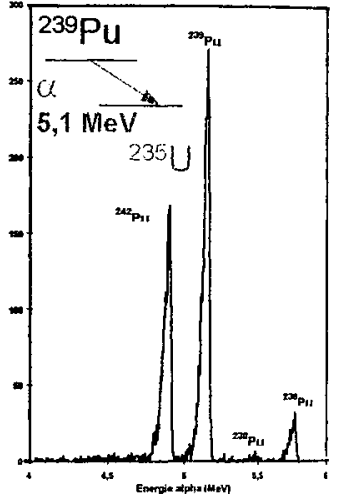

Figure 2: Alpha PIPS spectrum

\subsection{Beta Detection - Spectrometry}

In opposition to alpha/gamma spectrometry, pure beta emitters present continuous spectra. Litterature presents only approaches concerning the spectral beta total and gamma discrimination for the dosimetry [5]. Electrons can be discriminated through different characteristics: the shape, maximum beta energy of the transition, and if nuclides are also gamma emitters, conversion electron peaks $\left({ }^{137} \mathrm{Cs},{ }^{60} \mathrm{Co} . ..\right)$ could be used. As shown in Table 1, great differences appear between some major nuclides [6]:

Table 1: Sealed calibrated beta sources characteristics (energy in $\mathrm{keV}$ )

\begin{tabular}{|c|c|c|c|c|c|}
\hline Element & ${ }^{90} \mathrm{Sr}-{ }^{90} \mathrm{Y}$ & ${ }^{134} \mathrm{Cs}$ & ${ }^{137} \mathrm{Cs}$ & ${ }^{60} \mathrm{Co}$ & ${ }^{36} \mathrm{Cl}$ \\
\hline Activity (Bq) & $65 \mathrm{~Bq}$ & $128 \mathrm{~Bq}$ & $19800 \mathrm{~Bq}$ & $67 \mathrm{~Bq}$ & $4000 \mathrm{~Bq}$ \\
\hline $\begin{array}{c}\beta \text { max energy (keV) } \\
\text { (Intensity) }\end{array}$ & $2282(100 \%)$ & $\begin{array}{l}\text { a) } 658(70.2 \%) \\
\text { b) } 88(27.2 \%)\end{array}$ & $\begin{array}{l}\text { a) } 511(94.6 \%) \\
\text { b) } 1173(5.4 \%)\end{array}$ & $\begin{array}{l}\left.a^{\prime}\right) 318(99.9 \%) \\
\left.b^{\prime}\right) 1491(0.1 \%)\end{array}$ & $708(98.1 \%)$ \\
\hline $\begin{array}{c}\text { Average } \beta \text { energy } \\
\text { (keV) }\end{array}$ & 934 & $\begin{array}{l}\text { a) } 210 \\
\text { b) } 23 \\
\end{array}$ & $\begin{array}{l}\text { a) } 174 \\
\text { b) } 415\end{array}$ & $\begin{array}{r}\left.a^{\prime}\right) 96 \\
\text { b') } 627\end{array}$ & 247 \\
\hline $\begin{array}{c}\gamma \text { energy (keV) } \\
\text { (Intensity) }\end{array}$ & & $\begin{array}{c}796(85.5 \%) \\
605(97.6) \\
569(15.4) \\
\end{array}$ & $661(85.2 \%)$ & $\begin{array}{l}1173(99.9 \%) \\
1332(99.9 \%)\end{array}$ & \\
\hline
\end{tabular}

\section{3. ${ }^{137} \mathrm{Cs}$ example}

Frequently quantified in environmental samples by gamma spectrometry, ${ }^{137} \mathrm{Cs}$ is a beta emitter. Figure $\}$ represents the level scheme of this beta / gamma emitter. In addition to two beta rays, the $661 \mathrm{keV} \mathrm{V}^{13 \mathrm{Ba}}$ gamma transition is converted with a ratio of $8.94 \% \pm 0.1 \%$. The monokinetic eletrons $\left(655 \mathrm{keV}\left(\mathrm{K}_{\mathrm{k}}\right)\right.$ and $624 \mathrm{keV}\left(\mathrm{K}_{\beta}\right)$ ) and beta ray electrons (from 0 to $1173 \mathrm{keV}$ ) are emitted from a ${ }^{137} \mathrm{Cs}$ source.

Even if the electron range in silicon (1336 $\mu \mathrm{m}$ for $655 \mathrm{keV}$ electrons) is greater than the silion detector thickness $(300 \mu \mathrm{m})[7]$, two conversion electron peaks appear in the spectrum. This phenomena 
due to electron diffusion in matter with large diffusion angles. Peak resolutions at $624 \mathrm{keV}$ and $655 \mathrm{keV}$ are 18.5 et $19.1 \mathrm{keV}$ respectively.

The $1173 \mathrm{keV}$ beta maximum energy electrons can be observed in both detectors. In the beta ray energy region from 511 up to $1173 \mathrm{keV}$, both curve shapes are similar.

In the second detector, electron peak is shifted to a lower energy region $(515 \mathrm{keV})$. The difference between 624 and $515 \mathrm{keV}$ corresponds to the average energy loss for electrons crossing the first detector. Due to electron scattering, the energy straggling is observed through the resolution loss in the second detector.
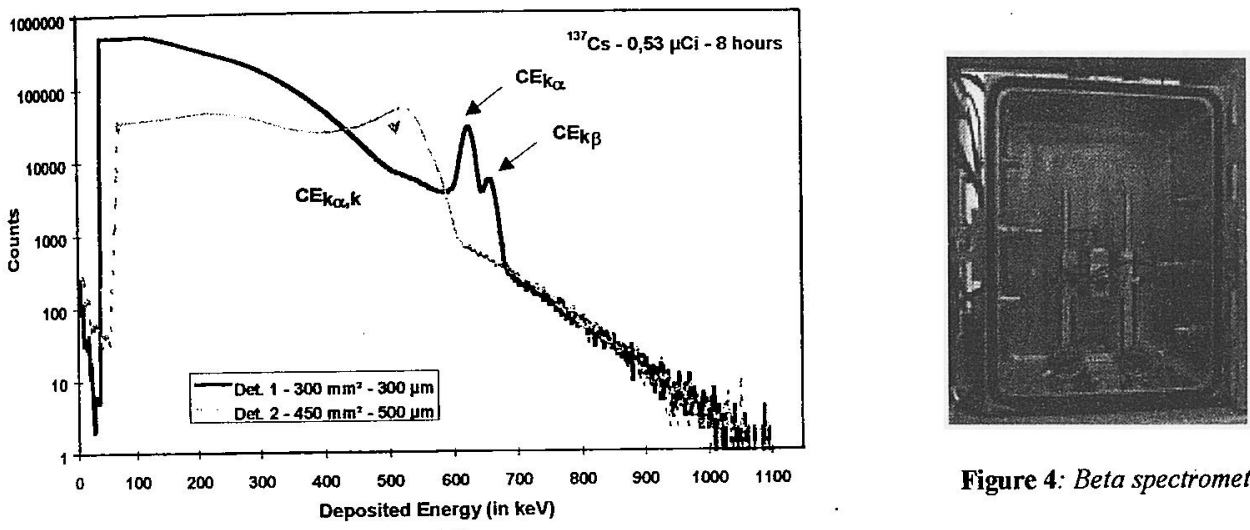

Figure 4: Beta spectrometer

Figure 3: Measured ${ }^{137} \mathrm{Cs}$ spectrum

\section{MATERIAL}

Detectors are set in a room located two stores below ground level under a $3 \mathrm{~m}$ thick boron concrete paving [8]. To reduce Radon concentration, external air filtering system is used in the measurement room. Room temperature is regulated by air conditioning.

\subsection{Counting box and detectors}

PIPS detectors are installed in a stainless steel protecting them from dust and beta particles ambiant air. A vaccum pump prevents radon emission inside the chamber.

The Canberra Planar Implanted Silicon detectors $\left(\right.$ PIPS $^{\circledR}$ ) used in this experiment are low-background with active area of $450 \mathrm{~mm}^{2}$ and $300 \mathrm{~mm}^{2}$ [9]. Two PIPS detectors are set up one on top of the other:

- the ring-shaped detector (det. 1 nearest of the source) has a $300 \mathrm{~mm}^{2}$ active area, and is $300 \mu \mathrm{m}$ thick. At normal incidence, the average electron loss is about $120 \mathrm{keV}$.

- the guard detector has $450 \mathrm{~mm}^{2}$ active area and $500 \mu \mathrm{m}$ thickness (Figure 3). Average energy loss is about $200 \mathrm{keV}$. Detectors and sources are disposed on shelves. All the system is fixed on a removable carrier. Calibrated wedges are used to vary the distances between each part of the system.

This assembling allows to minimize the distance between the two active areas, thus reduced to $2 \mathrm{~mm}$.

\subsection{Electronic}

The detectors are supplied and polarized by a high tension device (Canberra 3102D model). The detector polarization voltages are $+70 \mathrm{~V}$ for the $300 \mu \mathrm{m}$ detector and $+130 \mathrm{~V}$ for the $500 \mu \mathrm{m}$ detector. The signal is preamplified (Canberra 2003BT model), before being amplified (Canberra 2022 model). These standard devices are associated with a specific Fast Com Tec Wilkinson type ADC. A multiparametric software 
allows data acquistion resulting from both detectors and from the coincident events between both of them. More details on the equipment could be found in [10]

\subsection{Beta Sources and environmental sample}

${ }^{90} \mathrm{Sr}-{ }^{90} \mathrm{Y},{ }^{134} \mathrm{Cs},{ }^{137} \mathrm{Cs}$ and ${ }^{60} \mathrm{Co}$ sealed calibrated sources (CEA/DAMRI - France) are used (Table 1). A $4000 \mathrm{~Bq}{ }^{36} \mathrm{Cl}$ solution was precipitated on a stainless steel cupel. A $3 \mu \mathrm{m}$ Mylar layer was deposited on the source to avoid detector contamination. Counting time is fixed to 8 hours. Energy calibration is performed by ${ }^{207} \mathrm{Bi}$ (Amersham source) and ${ }^{137} \mathrm{Cs}$ conversion electrons, and by $59.9 \mathrm{keV}{ }^{241}$ Am gamma.

One aliquot of $5 \mathrm{~g}$ of certified IAEA-375 soil sample was used to measure beta radiation. A short radiochemistry (dissolution and mineralization) was carried out. Directly deposited on a stainless sted cupel, this source was counted over 7 days.

\subsection{Background}

Background spectra acquisitions were performed over 2.5 days. Figure 5 shows a typical background spectrum for both detector. Difference between spectra are due to the different active volume of silicon

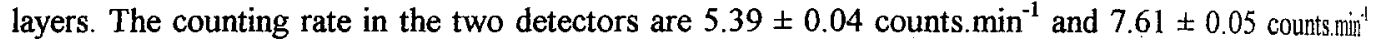
for det. 1 and det. 2 respectively.

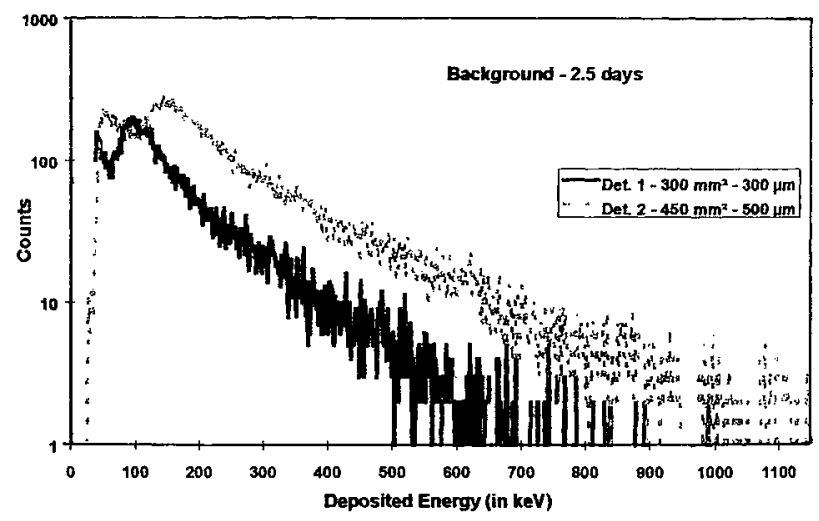

Figure 5: Background spectrum

\section{METHOD AND RESULTS}

Both aspects of this spectrometry can be illustrated by results obtained for pure sources like ${ }^{90} \mathrm{Sr}$ and ${ }^{36} \mathrm{Cl}$ and for an environmental sample (IAEA-375 certified sample).

\subsection{Pure source measurement}

Pure ${ }^{36} \mathrm{Cl}$ and ${ }^{90} \mathrm{Sr}$ beta sources were counted during 8 hours. ${ }^{36} \mathrm{Cl},{ }^{90} \mathrm{Sr} /{ }^{90} \mathrm{Y}$ and background spectra are presented in Figure 6 and Figure 7. Only the first detector spectrum is shown. Peaks that appear in the highest energy region are pulse generated. These peaks allow to check if an electronic drift occurred, and are used for time normalization. 


\subsection{1. ${ }^{36} \mathrm{Cl}$ source}

${ }^{30} \mathrm{Cl}$ intrinsic nuclear characteristic are observed in spectrum: beta end-point energy is present at 708 $\mathrm{keV}$. The minimum energy loss ( $120 \mathrm{keV}$, if initial energy is superior to $120 \mathrm{keV}$ ) is observed on this spectrum.

In comparison with background spectrum, no region are ${ }^{36} \mathrm{Cl}$ specific: background cover the total ${ }^{36} \mathrm{Cl}$ energy region (from 0 up to $708 \mathrm{keV}$ ). The 'a priori' minimum detectable activity is equal to $11 \mathrm{mBq}$ per sample - typically $500 \mathrm{mBq}$ per $\mathrm{kg}$ of dried environmental sample. This MDA is one order of magnitude better than our proportional counter [1].

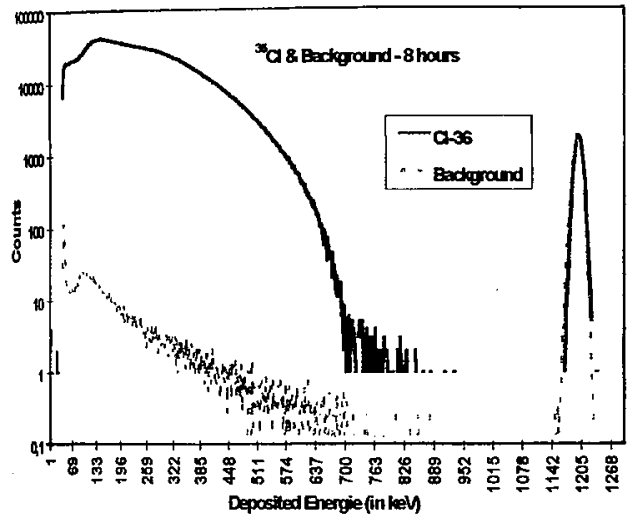

Figure 6: Measured ${ }^{36} \mathrm{Cl}$ source spectrum

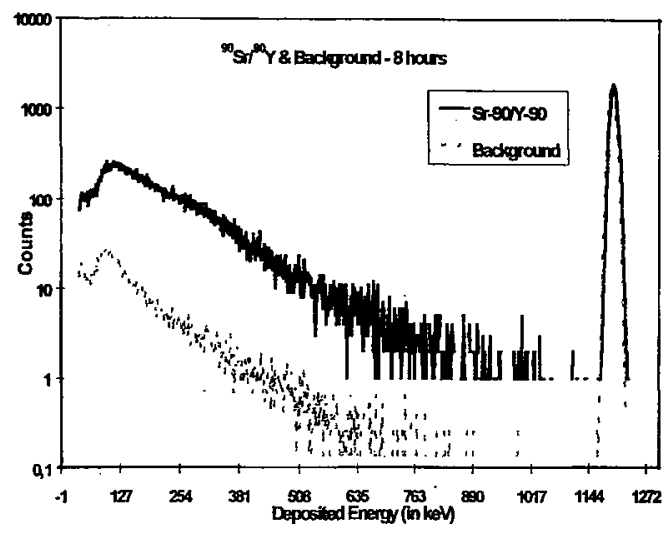

Figure 7: Measured ${ }^{90} \mathrm{Sr}^{\rho 0} \mathrm{Y}$ source spectrum

\subsection{2. ${ }^{90} \mathrm{Sr}{ }^{90} \mathrm{Y}$ source}

Up to $546 \mathrm{keV}$ is the ${ }^{90} \mathrm{Sr}$ contribution; above and up $2280 \mathrm{keV}$ is the ${ }^{90} \mathrm{Y}$ contribution. But the highest beta maximum energy is not visible in the det. 1 spectrum. Only up to $1150 \mathrm{keV}$ region is detected. This is due to insufficient silicon thickness to totally stop electrons with so high energy. However, in comparison with background spectrum, the region above $900 \mathrm{keV}$ is characteristic of the ${ }^{90} \mathrm{Sr}{ }^{\rho 0} \mathrm{Y}$ presence.

The 'a priori' minimum detectable activity is also equal to $1 \mathrm{mBq}$ per sample - typically $50 \mathrm{mBq}$ per $\mathrm{kg}$ of dried environmental sample ( 1 to 2 order of magnitude better compared to our proportional counting system).

\subsection{Multiemitter detection}

The multiemitter detection is based on the deconvolution of complex spectrum into single beta emitter spectra. As ${ }^{90} \mathrm{Y}$ is a high energy beta emitter, its contribution can be easily determined in the complex spectrum by fitting the curve on the highest energy region with a ${ }^{90} \mathrm{Sr} r{ }^{90} \mathrm{Y}$ reference. After substraction ${ }^{\circ f}$ the $\left.{ }^{90} \mathrm{Sr}\right)^{\rho 0} \mathrm{Y}$ contribution the major component in the spectrum is ${ }^{137} \mathrm{Cs}$. The conversion electron peak shows its presence even if conversion electron peak efficiency is poor. Finally, the simulated spectrum is rebuild with single beta emitter reference spectrum (Figure 8). ${ }^{85} \mathrm{Sr}$ tracer was used to determine radiochemistry yield. Its presence is revealed by a conversion electron peak at $508 \mathrm{keV}$. Lowest energy complex region deviates from single spectra due to electron self-attenuation in the source. Using ${ }^{90} \mathrm{Sr}{ }^{90} \mathrm{Y}$ reference spectrum, the ${ }^{90} \mathrm{Sr}$ activity of the IAEA-375 sample is $75 \mathrm{~Bq} \cdot \mathrm{kg}^{-1}$ compared to the $85 \mathrm{~Bq} \cdot \mathrm{kg}^{-1}$ teference value. 


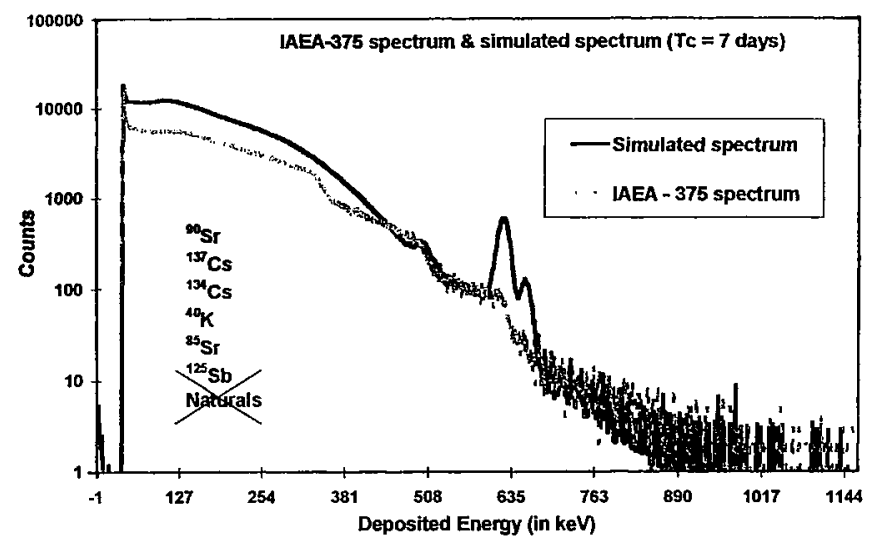

Figure 8: LAEA-375 soil sample spectrum

\section{CONCLUSION}

Usual counting technique requires extremes precautions in order to minimize interferences for pure bela emitter quantification: advanced radiochemistry for ${ }^{90} \mathrm{Sr}$, complementary analysis for ${ }^{36} \mathrm{Cl}$. In comparison, the spectrometry developed in this study allows to simplify the process by resolving these interferences at the time of measurement itself.

In accidental situation, sample sorting is performed by a gross beta measurement followed by complementary analytical techniques in order to identify major elements. In this case, the proposed spectrometry allows to discriminate immediately main beta emitter like ${ }^{131} \mathrm{I},{ }^{137} \mathrm{Cs},{ }^{134} \mathrm{Cs},{ }^{90} \mathrm{Sr} /{ }^{00} \mathrm{Y}$.

\section{Acknowledgments}

The authors are grateful to M. Mokili (CNRS/Subatech Nantes, France) for the ${ }^{36} \mathrm{Cl}$ source lending and P. Burger for PrPS detectors lending and useful discussions.

\section{References}

[1] Bouisset P., Goutelard F., Fournier M., Sharma P., Maro D., Calmet D., Proceeding "Jounées techniques de la CETAMA: Mesures et Analyses dans les matrices environnementales ef biologiques", Cadarache, 14-15 sept. 1999.

[2] Raab W., Parus J.L., Nucl. Instr. \& Meth. A339 (1994) 116-121.

[3] Bouisset P., Calmet D., Workshop on the status of measurement techniques for the identification of nuclear signatures, Proceedings Esarda Report EUR 17312, (Geel-Belgium, 25-27 feb. (1997)73-81.

[4] Gilmore G., Hemingway J., Practical Gamma-Ray Spectrometry, (J.Wiley \& Sons, Chichestet, 1995).

[5] Horowitz Y.S., Weizman Y., Hirning C.R., Nucl. Inst. \& Meth. A371 (1996) 522-534.

[6] Lederer C.M., Shirley V.S., Browne E., Dairiki J.M.and Doebler R.E., Table of Isotopes, (7th edition, John Wiley, New York, 1978).

[7] ICRU Report 37, ed. by International Commission on Radiation Units and Measurements (1984).

[8] Kerlau G., Cagnat X., Bouisset P., Barker E., Calmet D., Proceeding "Journées techniques de la CETAMA: Mesures et Analyses dans les matrices environnementales et biologiques", Cadarache, 14-15 sept. 1999.

[9] Burger P., Schoenmaekers W., Appl. Radiat.\& Isot. 356 (1994) 125-139.

[10] Courti A., Goutelard F., Burger P., Blotin E., Appl. Radiat.\& Isot. 53 (2000) 101-108. 